\title{
Increased blood glycohemoglobin A1c levels lead to overestimation of arterial oxygen saturation by pulse oximetry in patients with type 2 diabetes
}

\author{
Li Jin Pu ${ }^{1+}$, Ying Shen ${ }^{1+}$, Lin Lư ${ }^{1,2}$, Rui Yan Zhang ${ }^{1}$, Qi Zhang ${ }^{1}$ and Wei Feng Shen ${ }^{1,2^{*}}$
}

\begin{abstract}
Background: Non-enzymatic glycation increases hemoglobin-oxygen affinity and reduces oxygen delivery to tissues by altering the structure and function of hemoglobin.

Objectives: We investigated whether an elevated blood concentration of glycosylated hemoglobin (HbA1c) could induce falsely high pulse oximeter oxygen saturation $\left(\mathrm{SpO}_{2}\right)$ in type 2 diabetic patients during mechanical ventilation or oxygen therapy.

Methods: Arterial oxygen saturation $\left(\mathrm{SaO}_{2}\right)$ and partial pressure of oxygen $\left(\mathrm{PO}_{2}\right)$ were determined with simultaneous monitoring of $\mathrm{SpO}_{2}$ in 261 type 2 diabetic patients during ventilation or oxygen inhalation.

Results: Blood concentration of $\mathrm{HbA1c}$ was $>7 \%$ in 114 patients and $\leq 7 \%$ in 147 patients. Both $\mathrm{SaO}_{2}(96.2 \pm 2.9 \%$, $95 \%$ confidence interval [Cl] 95.7-96.7\% vs. $95.1 \pm 2.8 \%, 95 \% \mathrm{Cl}$ 94.7-95.6\%) and $\mathrm{SpO}_{2}(98.0 \pm 2.6 \%, 95 \% \mathrm{Cl} 97.6-98.5 \%$ vs. $95.3 \pm 2.8 \%, 95 \% \mathrm{Cl} 94.9-95.8 \%$ ) were significantly higher in patients with $\mathrm{HbA} 1 \mathrm{C}>7 \%$ than in those with $\mathrm{HbA1c} \leq 7 \%$ (Data are mean $\pm S \mathrm{~S}$, all $\mathrm{p}<0.01$ ), but $\mathrm{PO}_{2}$ did not significantly differ between the two groups. Bland-Altman analysis demonstrated a significant bias between $\mathrm{SpO}_{2}$ and $\mathrm{SaO}_{2}(1.83 \pm 0.55 \%, 95 \% \mathrm{Cl} 1.73 \%-1.94 \%)$ and limits of agreement $(0.76 \%$ and $2.92 \%)$ in patients with $\mathrm{HbA} 1 \mathrm{c}>7 \%$. The differences between $\mathrm{SpO}_{2}$ and $\mathrm{SaO}_{2}$ correlated closely with blood HbA1c levels (Pearson's $r=0.307, p<0.01$ ).

Conclusions: Elevated blood HbA1c levels lead to an overestimation of $\mathrm{SaO}_{2}$ by $\mathrm{SpO}_{2}$, suggesting that arterial blood gas analysis may be needed for type 2 diabetic patients with poor glycemic control during the treatment of hypoxemia.
\end{abstract}

Keywords: Glycohemoglobin A1c, Diabetes mellitus, Arterial blood gas analysis, Pulse oxygen saturation

\section{Background}

Glycohemoglobin is produced via a non-enzymatic reaction between the free aldehyde group of glucose or other sugars and the unprotonated form of free amino groups of hemoglobin [1]. Glycosylated hemoglobin A1c (HbAlc) is a stable minor hemoglobin variant separated by charge that is composed primarily but variably of glycohemoglobin. A clinical relationship between blood concentration of HbAlc and status of glycemic control has been elucidated [2], and elevated HbAlc levels

\footnotetext{
* Correspondence: rjshenweifeng@yahoo.com.cn

${ }^{\dagger}$ Equal contributors

'Department of Cardiology, Shanghai Rui Jin Hospital, Shanghai 200025, People's Republic of China

${ }^{2}$ Institute of Cardiovascular Diseases, School of Medicine, Shanghai Jiaotong University, Shanghai 200025, People's Republic of China
}

represent increased risk of coronary artery disease and poor outcome in diabetic patients [3-5]. Previous studies have shown that glycosylation alters the structure and function of hemoglobin [6,7] and tends to shift the oxygen dissociation curve to the left, leading to an increase in hemoglobin-oxygen affinity and a reduction in oxygen delivery to tissues $[6,8,9]$. Pulse oximetry is widely used as a noninvasive tool for continuous monitoring of artery oxygen saturation $\left(\mathrm{SaO}_{2}\right)[10,11]$, but pulse oximeter oxygen saturation $\left(\mathrm{SpO}_{2}\right)$ may overestimate arterial blood gases-determined $\mathrm{SaO}_{2}$ in acute sickle chest syndrome and severe sepsis [12,13]. So far, its accuracy for titrating fractional inspired oxygen in type 2 diabetic patients with mechanical ventilation or oxygen therapy remains unclear. Given that chronic hyperglycemia 
accelerates the accumulation of advanced glycation end products (AGE) in the skin collagen [14], which poses specific autofluorescence feature, may emit light by absorbing specific wavelengths light [15], and interfere with the accuracy of pulse oximetry, it is pertinent to examine if elevated blood $\mathrm{HbAlc}$ concentrations could result in an overestimation of $\mathrm{SaO}_{2}$ by $\mathrm{SpO}_{2}$ with finger probes particularly for type 2 diabetic patients with poor glycemic control.

\section{Methods}

\section{Study population}

A total of 261 consecutive type 2 diabetic patients undergoing oxygen therapy and/or mechanical ventilation from October 2010 to May 2012 in Rui Jin Hospital, Shanghai Jiaotong University School of Medicine were included. None had any recorded history of carbon monoxide exposure. The diagnosis of type 2 diabetes was made according to the criteria of American Diabetes Association, including symptoms of diabetes plus casual plasma glucose concentration beyond $200 \mathrm{mg} / \mathrm{dl}$ $(11.1 \mathrm{mmol} / \mathrm{l})$, or an increased fasting $(126 \mathrm{mg} / \mathrm{dl}$ [7.0 $\mathrm{mmol} / \mathrm{l}]$ ) or 2-hour postprandial glucose (2-h PG) level $(200 \mathrm{mg} / \mathrm{dl}[11.1 \mathrm{mmol} / \mathrm{l}]$ during an oral glucose tolerance test) [16]. Patients with type 1 diabetes were excluded by measurement of C-peptide. For the purpose of this study, we also excluded patients who were current cigarette smokers within 3 months or alcoholdependent, had renal insufficiency, anemia and fever, or were treated with vaso-constrictive agents. Poor glycemic control was defined as blood HbAlc level $>7 \%$ [17]. The study was approved by the hospital Institutional Review Board (IRB), and written informed consent was obtained from all participants.

\section{Biochemical assessments}

Peripheral venous blood was collected after an overnight fasting in all patients, and serum levels of glucose, blood urea nitrogen, creatinine, total cholesterol, low-density lipoprotein-cholesterol (LDL-C), highdensity lipoprotein cholesterol (HDL-C) and triglycerides were measured with standard laboratory techniques on a Hitachi 912 Analyzer (Roche Diagnostics, Germany). Hemoglobin concentrations were determined with a model T-890 Coulter (Beckman Coulter International, Nyon, Switzerland). In order to exclude individuals with abnormal hemoglobin, electrophoresis was carried out according to the method of MarengoRowe [18]. Blood HbA1c concentration was assayed using ion-exchange high performance liquid chromatography with a Bio-Rad Variant Hemoglobin Testing System (Bio-Rad Laboratories, Hercules, CA, USA). Levels of 2, 3-diphosphoglycerate (2,3-DPG) in the red blood cells were assayed within 15 min using enzymatic determination at $340 \mathrm{~nm}$ with an ultraviolet test kit from Roche Diagnostics (Roche Diagnostics GmbH, Mannheim, Germany) according to the manufacturer's instructions.

\section{Arterial blood gas analysis}

Arterial blood gases were determined during simultaneous $\mathrm{SpO}_{2}$ monitoring with pulse oximetry. Blood was drawn anaerobically into a preheparinized 1-mL syringe, and mixed well before measurement. After removal of all air bubbles from the syringe, in vivo $\mathrm{pH}$, partial pressure of carbon dioxide $\left(\mathrm{PCO}_{2}\right), \mathrm{SaO}_{2}$, partial pressure of oxygen $\left(\mathrm{PO}_{2}\right)$ and carboxyhemoglobin were directly measured using a Cobas b 221 blood gas analyzer (Roche Diagnostics, Germany). All measurements were completed within 5 min of blood sampling. Arterial blood gas analysis and $\mathrm{SpO}_{2}$ values were one measurement per patient.

\section{Monitoring of pulse oxygen saturation}

$\mathrm{SpO}_{2}$ was monitored continuously with a pulse oximetry (Nellcor NPB 40 MAX, Hayward, California), which detects oxygen saturation by measuring transdermal light absorption in the blood flow through a fingertip (DS 100A finger probe). $\mathrm{SpO}_{2}$ values were recorded only after a consistent reading, with a strong arterial waveform signal and a pulse reading identical to the patient's heart rate.

\section{Statistical analysis}

Baseline characteristics are expressed as mean and standard deviation (SD) for continuous variables, and percentages for categorical ones. Chi-square test was used to analyze dichotomous variables. Comparisons of continuous variables between groups were made by the appropriate Student's t tests. Correlation between difference $\left(\mathrm{SpO}_{2}-\mathrm{SaO}_{2}\right)$ and $\mathrm{HbA} 1 \mathrm{c}$ was analyzed using Pearson correlation coefficients. Accuracy $\left(\mathrm{SpO}_{2}-\mathrm{SaO}_{2}\right)$ of $\mathrm{SpO}_{2}$ was examined by the method of Bland and Altman analysis [19]. Bias was determined by the mean difference and 95\% confidence intervals $(\mathrm{CI})$ between $\mathrm{SpO}_{2}$ and $\mathrm{SaO}_{2}$, precision was determined by the standard deviation of the mean difference, and limits of agreement (mean difference $\pm 1.96 \mathrm{SD}$ ) was defined as a proportional function of distribution for differences between the 2 measurements. Data were analyzed using the Statistical Packages for Social Sciences (SPSS Version 13.0, Chicago, Ill). A 2 -tailed $\mathrm{p}$ value $<0.05$ was considered statistically significant. Only one measurement per patient for arterial blood gas and $\mathrm{SpO}_{2}$ was made.

\section{Results}

\section{Clinical characteristics}

Among overall 261 type 2 diabetic patients, 114 patients had a HbAlc $>7 \%$, and 147 had a HbA1c $\leq 7 \%$. Patients with HbAlc $>7 \%$ were older and had higher serum levels 
of fasting glucose, 2-h postprandial glucose, and triglycerides than those with HbA1c $\leq 7 \%$. The two groups did not differ with respect to occurrence rates of hypertension, chronic obstructive pulmonary disease, and pulmonary edema (Table 1).

Arterial blood gas profiles, pulse oximetry, and 2, 3-DPG Both $\mathrm{SaO}_{2}(96.2 \pm 2.9 \%, 95 \%$ confidence interval [CI] 95.7-96.7\% vs. $95.1 \pm 2.8 \%$, 95\% CI 94.7-95.6\%) and $\mathrm{SpO}_{2}$

Table 1 Baseline characteristiecs and biochemical assessments

\begin{tabular}{|c|c|c|c|}
\hline Variables & $\begin{array}{l}\mathrm{HbA} 1 \mathrm{c} \leq 7 \% \\
(\mathrm{n}=147)\end{array}$ & $\begin{array}{l}\mathrm{HbA} 1 \mathrm{c}>7 \% \\
(n=114)\end{array}$ & P Value \\
\hline Male gender (\%) & 104(70.7) & $78(68.4)$ & 0.685 \\
\hline Age (yrs) & $67 \pm 6$ & $69 \pm 7$ & 0.01 \\
\hline $\begin{array}{l}\text { Chronic obstructive } \\
\text { pulmonary disease (\%) }\end{array}$ & $98(66.7)$ & $81(71.1)$ & 0.449 \\
\hline $\begin{array}{l}\text { Cardiogenic pulmonary } \\
\text { edema }(\%)\end{array}$ & $13(8.8)$ & $17(14.9)$ & 0.127 \\
\hline Pneumonia (\%) & $40(27.2)$ & $46(40.4)$ & 0.025 \\
\hline Hypertension (\%) & $49(33.3)$ & $40(35.1)$ & 0.243 \\
\hline $\begin{array}{l}\text { Systolic blood pressure } \\
(\mathrm{mmHg})\end{array}$ & $131 \pm 9$ & $132 \pm 9$ & 0.374 \\
\hline $\begin{array}{l}\text { Diastolic blood pressure } \\
(\mathrm{mmHg})\end{array}$ & $75 \pm 8$ & $76 \pm 8$ & 0.317 \\
\hline Red blood cell (x10 $12 / L)$ & $4.75 \pm 0.73$ & $4.91 \pm 0.77$ & 0.088 \\
\hline Hemoglobin (g/L) & $132 \pm 12$ & $134 \pm 13$ & 0.199 \\
\hline Body temperature $\left({ }^{\circ} \mathrm{C}\right)$ & $37.3 \pm 0.1$ & $37.4 \pm 0.1$ & $<0.001$ \\
\hline Total cholesterol (mmo1/L) & $4.06 \pm 0.91$ & $4.17 \pm 0.95$ & 0.343 \\
\hline HDL-cholesterol (mmo1/L) & $1.19 \pm 0.26$ & $1.17 \pm 0.27$ & 0.545 \\
\hline LDL-cholesterol (mmo1/L) & $2.43 \pm 0.62$ & $2.41 \pm 0.68$ & 0.805 \\
\hline Triglycerides (mmo1/L) & $1.72 \pm 0.75$ & $1.91 \pm 0.78$ & 0.047 \\
\hline Fasting Glucose (mmo1/L) & $5.9 \pm 1.8$ & $9.4 \pm 2.1$ & $<0.001$ \\
\hline $\begin{array}{l}\text { 2-h postprandial glucose } \\
\text { (mmo1/L) }\end{array}$ & $9.2 \pm 4.1$ & $13.9 \pm 4.5$ & $<0.001$ \\
\hline $\mathrm{HbA1c}(\%)$ & $5.6 \pm 1.2$ & $9.2 \pm 2.1$ & $<0.001$ \\
\hline $\begin{array}{l}\text { Blood urea nitrogen } \\
(\mathrm{mmo1/L)}\end{array}$ & $5.42 \pm 2.35$ & $6.03 \pm 2.51$ & 0.045 \\
\hline Creatinine ( $\mu \mathrm{mo1} / \mathrm{L})$ & $87 \pm 16$ & $91 \pm 18$ & 0.59 \\
\hline \multicolumn{4}{|l|}{ Medical treatments } \\
\hline ACEl or ARB (\%) & $46(31.3)$ & $37(32.5)$ & 0.841 \\
\hline $\begin{array}{l}\text { Calcium channel } \\
\text { blocker (\%) }\end{array}$ & $14(9.5)$ & $12(10.5)$ & 0.789 \\
\hline Statins* $(\%)$ & $121(82.3)$ & $97(85.1)$ & 0.549 \\
\hline Metformin (\%) & $52(35.4)$ & $45(39.5)$ & 0.497 \\
\hline Sulphonylureas (\%) & $56(38.1)$ & $37(32.5)$ & 0.345 \\
\hline Alpha-glucosidase (\%) & $54(36.7)$ & $46(40.3)$ & 0.551 \\
\hline PPAR-gamma agonist (\%) & $23(15.6)$ & $15(13.2)$ & 0.572 \\
\hline $\begin{array}{l}\text { Data are mean } \pm \text { SD or numbe } \\
\text { Abbreviation: } \mathrm{HbA} 1 \mathrm{c} \text {, Glycosyla } \\
\text { lipoprotein. } \\
\mathrm{LDL} \text {, low-density lipoprotein; A } \\
\text { ARB, angiotensin II receptor bl }\end{array}$ & $\begin{array}{l}\text { \%). } \\
\text { d hemoglobin } \\
\text { l, andgiotensin } \\
\text { ker. }\end{array}$ & $\begin{array}{l}\text { n HDL, High-der } \\
\text { nverting enzym }\end{array}$ & $\begin{array}{l}\text { ity } \\
\text { inhibitor. }\end{array}$ \\
\hline
\end{tabular}

$(98.0 \pm 2.6 \%, 95 \%$ CI $97.6-98.5 \%$ vs. $95.3 \pm 2.8 \%, 95 \%$ CI 94.9-95.8\%) were significantly higher in patients with HbA1c $>7 \%$ than in those with $\mathrm{HbA1c} \leq 7 \%$ (Data are mean $\pm \mathrm{SD}$, all $\mathrm{p}<0.01$ ), but $\mathrm{PO}_{2}$ did not significantly differ between the two groups.

Levels of 2, 3-DPG in the red blood cells and $\mathrm{PCO}_{2}$ were slightly elevated in patients with $\mathrm{HbA1c}>7 \%$, but did not reach statistical significance levels ( $p>0.05)$. Body temperature, $\mathrm{pH}$, and carboxyhemoglobin were similar in the two groups (Table 2).

The difference between $\mathrm{SpO}_{2}$ and $\mathrm{SaO}_{2}$ correlated closely with blood HbA1c levels (Pearson's $\mathrm{r}=0.307, \mathrm{p}<$ 0.01) (Figure 1).

\section{Arterial oxyhemoglobin sigmoid curves}

The sigmoid fitted curve for patients with HbA1c $>7 \%$ shifted to the left compared with that with $\mathrm{HbA} 1 \mathrm{c} \leq 7 \%$. The mean difference of $\mathrm{SaO}_{2}$ between diabetic patients with $\mathrm{HbA} 1 \mathrm{c}>7 \%$ and those with $\mathrm{HbA} 1 \mathrm{c} \leq 7 \%$ was $1.1 \%$ (Figure 2).

\section{Bland-Altman analysis}

The simultaneous readings of $\mathrm{SaO}_{2}$ and $\mathrm{SpO}_{2}$ were analyzed to determine the bias and limits of agreement. Bland-Altman analysis indicated that the bias (mean difference of $\mathrm{SpO}_{2}$ minus $\mathrm{SaO}_{2}$ ) between the two methods was $1.83 \pm 0.55 \%(95 \%$ CI $1.73 \%-1.94 \%)$ and limits of agreement were $0.76 \%$ and $2.92 \%$ in patients with HbA1c $>7 \%$ (Figure 3). Overall, there was a significant bias between pulse oximetry and arterial blood gases in patients with HbA1c $>7 \%$.

\section{Discussion}

The present study is the first to demonstrate that despite similar levels of red blood cell 2, 3-DPG, $\mathrm{PO}_{2}, \mathrm{PCO}_{2}, \mathrm{pH}$ and body temperature, type 2 diabetic patients with HbA1c $>7 \%$ had higher $\mathrm{SaO}_{2}$ (the mean difference was

Table 2 Arterial blood gas analysis, 2,3-DPG level and $\mathrm{SpO}_{2}$ between two groups

\begin{tabular}{llll}
\hline Variables & $\begin{array}{l}\mathbf{H b A 1 c} \leq \mathbf{7 \%} \\
(\mathbf{n = 1 4 7 )}\end{array}$ & $\begin{array}{l}\mathbf{H b A 1 c > 7 \%} \\
(\mathbf{n}=\mathbf{1 1 4})\end{array}$ & P Value \\
\hline $2,3-\mathrm{DPG}(\mu \mathrm{mo} 1 / \mathrm{gHb})$ & $13.9 \pm 1.7$ & $14.2 \pm 1.7$ & 0.09 \\
\hline $\mathrm{pH}$ & $7.37 \pm 0.05$ & $7.39 \pm 0.05$ & 0.01 \\
\hline $\mathrm{PCO}_{2}(\mathrm{Kpa})$ & $5.48 \pm 0.73$ & $5.53 \pm 0.65$ & 0.565 \\
\hline $\mathrm{Carboxyhemoglobin}(\%)$ & $1.08 \pm 0.81$ & $1.09 \pm 0.78$ & 0.92 \\
\hline $\mathrm{PO}_{2}(\mathrm{Kpa})$ & $10.0 \pm 1.9$ & $10.0 \pm 2.2$ & 0.843 \\
\hline $\mathrm{SaO}_{2}(\%)$ & $95.1 \pm 2.8$ & $96.2 \pm 2.9$ & 0.002 \\
\hline $\mathrm{SpO}_{2}(\%)$ & $95.3 \pm 2.8$ & $98.0 \pm 2.6$ & 0.001 \\
\hline $\mathrm{Da}^{2}$
\end{tabular}

Data are mean \pm SD.

Abbreviation: 2,3-DPG, 2, 3-diphosphosglycerate.

$\mathrm{PCO}_{2}$, partial pressure of carbon dioxide.

$\mathrm{PO}_{2}$, partial pressure of oxygen; $\mathrm{SaO}_{2}$, arterial oxygen saturation.

$\mathrm{SpO}_{2}$, pulse oximeter oxygen saturation. 


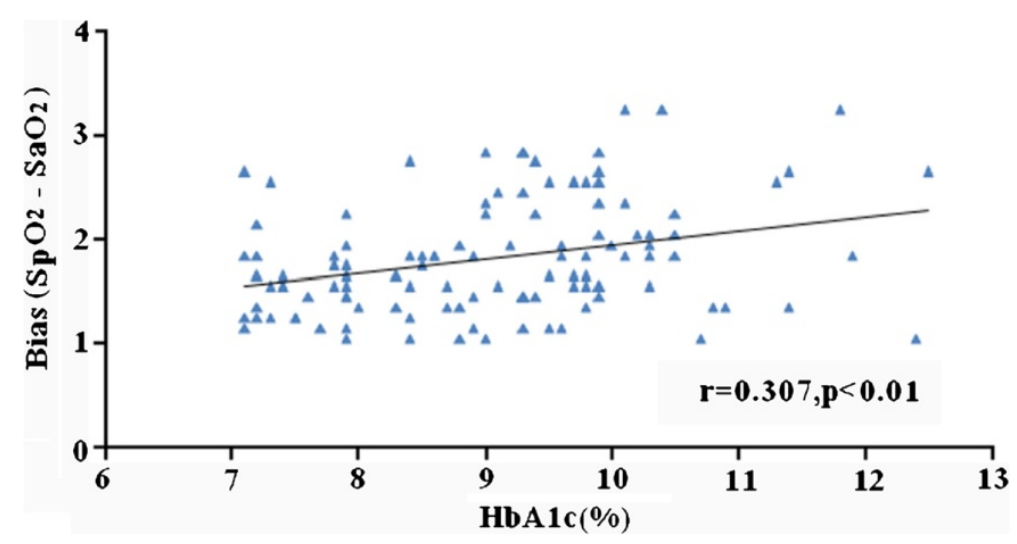

Figure 1 Correlation of the difference between $\mathrm{SpO}_{2}$ and $\mathrm{SaO}_{2}$ with blood $\mathrm{HbA} 1 \mathrm{c}$ levels in patients with poor glycemic control.

$1.1 \%)$ and bias $(1.83 \pm 0.55 \%)$ compared with those with HbA1c $\leq 7 \%$, suggesting that elevated blood HbAlc levels led to an overestimation of $\mathrm{SaO}_{2}$ by pulse oximetry.

Hypoxemia denotes a condition that is characterized by low oxygen content or percent saturation of hemoglobin with oxygen [13]. Arterial blood gases have been traditionally used to assess the status of oxygenation and to adjust fractional inspired oxygen in patients receiving mechanical ventilation or oxygen therapy [20]. Currently, noninvasive continuous monitoring of $\mathrm{SaO}_{2}$ with $\mathrm{SpO}_{2}$ has become the standard care for patients with critical conditions $[13,21]$, to decrease the likelihood of hypoxemia [22-25] and to wean mechanical ventilation $[10,11,26]$. In the present study, when comparisons were performed at identical $\mathrm{PO}_{2}, \mathrm{SaO}_{2}$ was higher in type 2 diabetic patients with $\mathrm{HbA1c}>7 \%$, which is likely due to an increased hemoglobin-oxygen affinity. Our results are in line with previous findings that higher blood concentrations of HbA1c significantly reduce oxygen dissociation velocity [27]. Although the exact mechanism remains not fully understood, it may be, at least partly, explained by glycation of multiple $\beta$ - chain sites of hemoglobin A molecule, accompanied by increasing -chain glycation at high glycohemoglobin concentrations $[28,29]$.

The major finding of this study is that in type 2 diabetic patients with poor glycemic control, pulse oximetry overestimated arterial blood gases-determined $\mathrm{SaO}_{2}$ by a mean of $2.7 \%$ when compared with those with HbA1c $\leq$ 7\%. Previous studies showed that older women have higher HbA1c than men, even after controlling for body mass index [30], and accumulation of AGE in human skin collagen is age-dependent [31]. However, both gender distribution and age did not significantly differ between the two groups in the present study, suggesting that the difference between $\mathrm{SpO}_{2}$ and $\mathrm{SaO}_{2}$ may be mainly related to $\mathrm{HbA1c}$ levels as higher HbA1c levels were associated with great differences (Pearson's $r=$ 0.307, $\mathrm{p}<0.01$ ).

Our findings may be of important clinical relevance. First, falsely high $\mathrm{SpO}_{2}$ could cause under-diagnosis of hypoxemia in type 2 diabetic patients. Second, because a greater $\mathrm{SpO}_{2}$ was required to achieve the same arterial blood gases-determined $\mathrm{PO}_{2}$ for diabetic patients with

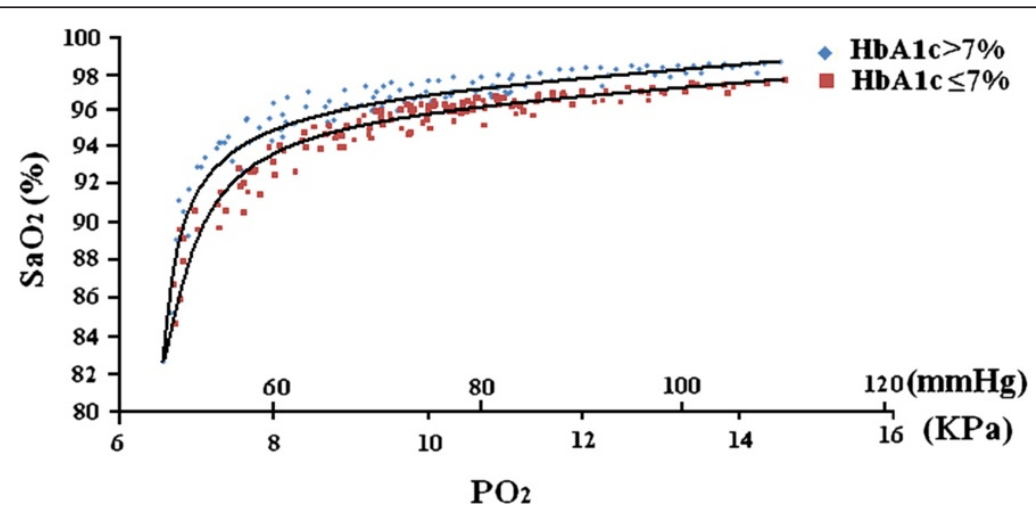

Figure 2 Arterial oxyhemoglobin sigmoid curves $\left(\mathrm{PO}_{2}\right.$, partial pressure of oxygen; $\mathrm{SaO}_{2}$, arterial oxygen saturation). 


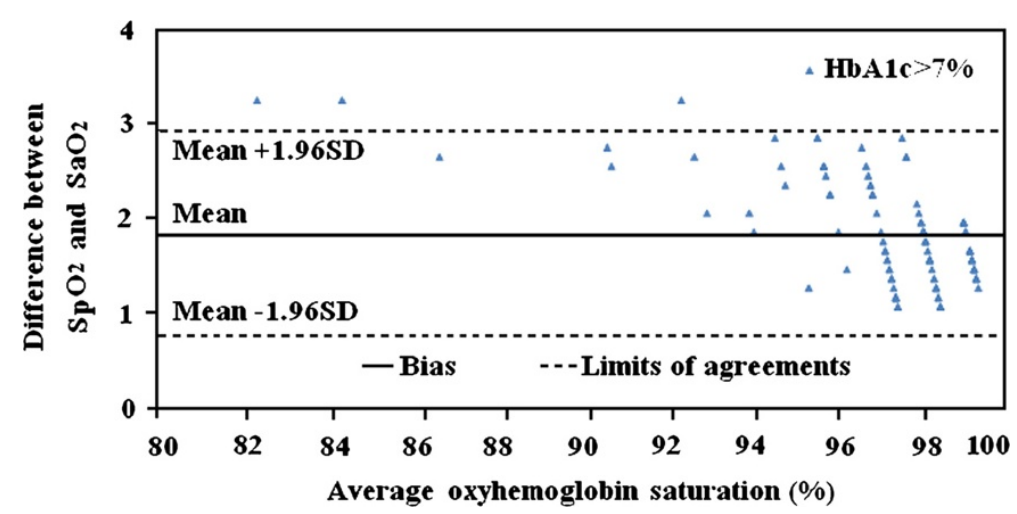

Figure 3 Bland-Altman plots for bias and limits of agreement in patients with poor glycemic control.

HbA1c $>7 \%$ compared with those with HbA1c $\leq 7 \%$, care should be taken in adjusting oxygen supply during mechanical ventilation or oxygen therapy. The reason for a higher $\mathrm{SpO}_{2}$ than $\mathrm{SaO}_{2}$ may be partly explained by an extensive accumulation of AGE in the skin collagen in patients with poor glycemic control [14], interfering with transdermal absorption of the specific wavelength light by hemoglobin with finger probes [12,32]. These observations support a notion that the causes of high bias does include skin effect [33,34], and when $\mathrm{SaO}_{2}$ needs to be determined with a high degree of accuracy, arterial blood gases are recommended in type 2 diabetic patients with poor glycemic control.

\section{Limitations}

Due to relatively small sample size, potential for selection bias may raise some concerns on the statistical precision of the estimates. A large-scale study is warranted to confirm our findings. The other major limitation is that most of the data are at high $\mathrm{SaO}_{2}$ because of a specially selected study population as all patients were receiving mechanical ventilation and/or oxygen therapy. The oxyhemoglobin dissociation curves could actually be fitted with non-linear regression, and a partial pressure of oxygen in blood associated to a hemoglobin oxygen saturation of $50 \%$ (P50) could also be calculated [35]. Most oximetry testing intentionally gathers data below $90 \%$ by performing desaturation experiments in volunteers. Gather multiple data points on volunteers increase the data set substantially, and allow one to test over a wide range of $\mathrm{SaO}_{2}$, and control for other effects. By creating a gas pocket with $\mathrm{CO}_{2}$ and $\mathrm{O}_{2} / \mathrm{N}_{2}$ mixtures, one can create a much more detailed oxyhemoglobin dissociation curve. The US FDA requires testing balanced by gender and ethnicity. Repeated measures statistics would then be necessary, and P50 is not determined quite as precisely unless the sample is near a $\mathrm{SaO}_{2}$ of $50 \%$. Certainly, it remains unclear whether the issue with diabetic patients would be safe given the possibility of cardiovascular disease, although younger subjects could be reasonable.

\section{Conclusions}

Elevated blood $\mathrm{HbA1c}$ concentrations lead to an overestimation of $\mathrm{SaO}_{2}$ by $\mathrm{SpO}_{2}$, suggesting that arterial blood gas analysis may be needed for type 2 diabetic patients with poor glycemic control during the treatment of hypoxemia.

\section{Abbreviations}

AGE: Advanced glycation end products; 2, 3-DPG: 2, 3-diphosphoglycerate; $\mathrm{Cl}$ : Confidence interval; HbAlc: Glycosylated hemoglobin A1c; HDL: Highdensity lipoprotein; LDL: Lower-density lipoprotein; $\mathrm{PCO}_{2}$ : Partial pressure of carbon dioxide; $\mathrm{PO}_{2}$ : Partial pressure of oxygen; $\mathrm{SaO}_{2}$ : Arterial oxygen saturation; SD: Standard deviation; $\mathrm{SpO}_{2}$ : Pulse oximeter oxygen saturation.

\section{Competing interests}

The authors declare that they have no competing interests.

\section{Authors' contributions}

LJP designed the study and drafted the manuscript; YS collected the samples and performed the experiments; LL participated in the whole process of experiments; RYZ and QZ contributed to data analysis; WFS was responsible for the whole research project and prepared the manuscript. All authors have read and approved the final manuscript.

\section{Acknowledgements and funding}

This study was supported by a grant from Shanghai Municipal Science and Technology Committee (10JC1410500).

Received: 14 September 2012 Accepted: 15 September 2012

Published: 17 September 2012

\section{References}

1. Miedema K: Electrospray mass spectrometry for measurement of glycohemoglobin. Clin Chem 1997, 43:705-707.

2. American Diabetes Association: Clinical practice recommendations. Diabetes Care 2000, 23:S32-42.

3. Daida H, Takayama T, Hiro T, Yamagishi M, Hirayama A, Saito S, Yamaguchi T, Matsuzaki M: High HbA1c levels correlate with reduced plaque regression during statin treatment in patients with stable coronary artery disease: Results of the coronary atherosclerosis study measuring effects of rosuvastatin using intravascular ultrasound in Japanese subjects (COSMOS). Cardiovasc Diabetol 2012, 11:87.

4. Nishimura R, Nakagami T, Sone H, Ohashi Y, Tajima N: Relationship between hemoglobin A1c and cardiovascular disease in mild-tomoderate hypercholesterolemic Japanese individuals: subanalysis of a large-scale randomized controlled trial. Cardiovasc Diabetol 2011, 10:58. 
5. Ikeda N, lijima R, Hara H, Moroi M, Nakamura M, Sugi K: Glycated hemoglobin is associated with the complexity of coronary artery disease, even in non-diabetic adults. J Atheroscler Thromb 2012, 19 [Epub ahead of print].

6. De Rosa MC, Sanna MT, Messana I, Castagnola M, Galtieri A, Tellone E, Scatena R, Botta B, Botta M, Giardina B: Glycated human hemoglobin (HbA1c): functional characteristics and molecular modeling studies. Biophys Chem 1998, 72:323-335.

7. Samaja M, Melotti D, Carenini A, Pozza G: Glycosylated haemoglobins and the oxygen affinity of whole blood. Diabetologia 1982, 23:399-402.6

8. Bunn HF: The glycosylation of hemoglobin: relevance to diabetes mellitus. Science 1978, 200:21-27.

9. Ditzel J: Affinity hypoxia as a pathogenic factor of microangiopathy with particular reference to diabetic retinopathy. Acta Endocrinologica Supplementum 1980, 238:39-55.

10. Jubran A, Tobin MJ: Reliability of pulse oximetry in titrating supplemental oxygen therapy in ventilator-dependent patients. Chest 1990, 97:1420-1425.

11. Moloney ED, Kiely JL, McNicholas WT: Controlled oxygen therapy and carbon dioxide retention during exacerbations of chronic obstructive pulmonary disease. Lancet 2001, 357:526-528.

12. Kress JP, Pohlman AS, Hall JB: Determination of hemoglobin saturation in patients with acute sickle chest syndrome: a comparison of arterial blood gases and pulse oximetry. Chest 1999, 115:1316-1320.

13. Wilson BJ, Cowan HJ, Lord JA, Zuege DJ, Zygun DA: The accuracy of pulse oximetry in emergency department patients with severe sepsis and septic shock: a retrospective cohort study. BMC Emerg Med 2010, 10:9.

14. Dyer DG, Dunn JA, Thorpe SR, Bailie KE, Lyons TJ, McCance DR, Baynes JW: Accumulation of Maillard reaction products in skin collagen in diabetes and aging. J Clin Invest 1993, 91:2463-2469.

15. Bos DC, de Ranitz-Greven WL, de Valk HW: Advanced glycation end products, measured as skin autofluorescence and diabetes complications: a systematic review. Diabetes Technol Ther 2011 13:773-779.

16. Expert Committee on the Diagnosis and Classification of Diabetes Mellitus: Report of the expert committee on the diagnosis and classification of diabetes mellitus. Diabetes Care 2003, 26(Suppl 1):S5-20.

17. Kassaian SE, Goodarzynejad H, Boroumand MA, Salarifar M, Masoudkabir F, Mohajeri-Tehrani MR, Pourhoseini H, Sadeghian S, Ramezanpour N, Alidoosti M, Hakki E, Saadat S, Nematipour E: Glycosylated hemoglobin (HbA1c) levels and clinical outcomes in diabetic patients following coronary artery stenting. Cardiovasc Diabetol 2012, 11:82.

18. Marengo-Rowe AJ: Rapid electrophoresis and quantitation of hemoglobin on cellulose acetate. J Clin Pathol 1965, 18:790-792.

19. Bland JM, Altman DG: Measuring agreement in method comparison studies. Stat Methods Med Res 1999, 8:161-179.

20. de Jonge E, Peelen L, Keijzers PJ, Joore H, de Lange D, van der Voort PH, Bosman RJ, de Waal RA, Wesselink R, de Keizer NF: Association between administered oxygen, arterial partial oxygen pressure and mortality in mechanically ventilated intensive care unit patients. Crit Care 2008, 12:R156.

21. Birnbaum S: Pulse oximetry: identifying its applications, coding, and reimbursement. Chest 2009, 135:838-841.

22. Van de Louw A, Cracco C, Cerf C, Harf A, Duvaldestin P, Lemaire F, Brochard $\mathrm{L}$ : Accuracy of pulse oximetry in the intensive care unit. Intensive Care Med 2001, 27:1606-1613.

23. Lee WW, Mayberry K, Crapo R, Jensen RL: The accuracy of pulse oximetry in the emergency department. Am J Emerg Med 2000, 18:427-431.

24. Seguin P, Le Rouzo A, Tanguy M, Guillou YM, Feuillu A, Malledant Y: Evidence for the need of bedside accuracy of pulse oximetry in an intensive care unit. Crit Care Med 2000, 28:703-706.

25. Jubran A: Pulse oximetry. Intensive Care Med 2004, 30:2017-2020.

26. Mihm FG, Halperin BD: Noninvasive detection of profound arterial desaturations using a pulse oximetry device. Anesthesiology 1985, 62:85-87.

27. Marschner JP, Seidlitz T, Rietbrock N: Effect of 2,3-diphosphoglycerate on $\mathrm{O}_{2}$-dissociation kinetics of hemoglobin and glycosylated hemoglobin using the stopped flow technique and an improved in vitro method for hemoglobin glycosylation. Int J Clin Pharmacol Ther 1994, 32:116-121.
28. Peterson KP, Pavlovich JG, Goldstein D, Little R, England J, Peterson CM: What is hemoglobin A1c? An analysis of glycated hemoglobins by electrospray ionization mass spectrometry. Clin Chem 1998, 44:1951-1958.

29. Roberts NB, Amara AB, Morris M, Green BN: Long-term evaluation of electrospray ionization mass spectrometric analysis of glycated hemoglobin. Clin Chem 2001, 47:316-321.

30. Martins RA, Jones JG, Cumming SP, Coelho e Silva MJ, Teixeira AM, Veríssimo MT: Glycated hemoglobin and associated risk factors in older adults. Cardiovasc Diabetol 2012, 11:13.

31. Dunn JA, McCance DR, Thorpe SR, Lyons TJ, Baynes JW: Age-dependent accumulation of $\mathrm{N}^{\varepsilon}$-(carboxymethyl)lysine and $\mathrm{N}^{\varepsilon}$-(carboxymethyl) hydroxylysine in human skin collagen. Biochemistry 1991, 30:1205-1210.

32. Gerrits EG, Lutgers HL, Kleefstra N, Graaff R, Groenier KH, Smit AJ, Gans RO, Bilo HJ: Skin autofluorescence: a tool to identify type 2 diabetic patients at risk for developing microvascular complications. Diabetes Care 2008, 31:517-521.

33. Bickler PE, Feiner JR, Severinghaus JW: Effects of skin pigmentation on pulse oximeter accuracy at low saturation. Anesthesiology 2005, 102:715-719.

34. Feiner JR, Severinghaus JW, Bickler PE: Dark skin decreases the accuracy of pulse oximeters at low oxygen saturation: the effects of oximeter probe type and gender. Anesth Analg 2007, 105:S18-23.

35. Severinghaus JW: Simple, accurate equations for human blood $\mathrm{O}_{2}$ dissociation computations. J Appl Physiol 1979, 46:599-602.

doi:10.1186/1475-2840-11-110

Cite this article as: Pu et al:: Increased blood glycohemoglobin A1c levels lead to overestimation of arterial oxygen saturation by pulse oximetry in patients with type 2 diabetes. Cardiovascular Diabetology 2012 11:110.

\section{Submit your next manuscript to BioMed Central and take full advantage of:}

- Convenient online submission

- Thorough peer review

- No space constraints or color figure charges

- Immediate publication on acceptance

- Inclusion in PubMed, CAS, Scopus and Google Scholar

- Research which is freely available for redistribution 